\title{
Ethical dilemmas in the era of COVID-19
}

\author{
Hassan Chamsi-Pasha, Majed Chamsi-Pasha ${ }^{1}$, Mohammed A. Albar $^{2}$
}

Department of Cardiology, King Fahd Armed Forces Hospital, Jeddah, Saudi Arabia, ${ }^{1}$ Department of Medicine, International Medical Center, Jeddah, Saudi-Arabia, ${ }^{2}$ Department of Medical Ethics, International Medical Center, Jeddah, Saudi Arabia

\begin{tabular}{|c|}
\hline Access this article online \\
\hline Website: www.avicennajmed.com \\
\hline DOI: 10.4103/ajm.ajm_119_20 \\
\hline Quick Response Code: \\
\hline
\end{tabular}

\section{ABSTRACT}

The coronavirus disease 2019 (COVID-19) pandemic placed an extraordinary demand on health systems and healthcare providers all over the world. The pandemic presented a number of unprecedented challenging ethical issues. Across the globe, hospitals are being challenged by a large number of patients presenting to the emergency room for treatment, creating scarcities of critical care resources, and uncovering the need for formal crisis standards of care. Difficult life and death decisions, which may create severe moral distress to the physicians, have to be made in emergency rooms and intensive care units. Other ethical issues, such as that related to conducting clinical trials during the pandemic, and the increase in domestic violence during the quarantine period, will be also discussed.

Key words: Coronavirus disease 2019, ethical challenges, medical ethics, scarce resources

\section{INTRODUCTION}

The coronavirus disease 2019 (COVID-19) has grasped the world in a firm grip, and individuals everywhere face unprecedented challenges in providing the best health care. Healthcare organizations, across the world, have been rapidly reacting to different medical, ethical, and social challenges imposed by the pandemic. Lockdowns have an impact on the health and disease of hundreds of millions of people confined to homes. Hospitals have shown great flexibility, with many elective operations and outpatient clinics widely canceled. The COVID-19 has already created ethical questions about the need for prioritization of treatment, availability of personal protective equipment, testing, and resuscitation decisions. Ethical challenges continue to emerge as the pandemic continues to progress, ${ }^{[1]}$ including how best to deal with research on additional vaccine when an effective product is already in hands, and how to prioritize patients for medical care as medical services reopen.

\section{SCARCE RESOURCES ALLOCATION}

The ethical implications of scarce resources are very drastic in this COVID-19 pandemic. The great demand for critical

Address for correspondence: Dr. Hassan Chamsi-Pasha, Department of Cardiology, King Fahd Armed Forces Hospital, P.O. Box: 9862, Jeddah 21159, Saudi Arabia.

E-mail: drhcpasha@hotmail.com care services in several areas of the world, such as the northern region of Italy and New York, was exceeding the supply. Intensive care doctors were facing challenging decisions about who should receive a ventilator or not, knowing the fact that those who are not admitted to the intensive care units will very likely die. Physicians have to consider the prioritization of patients who are most likely to survive over those with remote chances. This practice has stimulated an immense debate about the right of everyone to get access to the health care. ${ }^{[2]}$ Priority decisions, if required, will be delegated to the skillful physicians who will wisely utilize the resources available to them.

The University of Pittsburgh, the Washington University, and the State of New York, have all created models with assigning scores to the patients, based on their age and comorbidities, which guide the clinicians in the allocation of scarce resources. ${ }^{[3]}$

This is an open access journal, and articles are distributed under the terms of the Creative Commons Attribution-NonCommercial-ShareAlike 4.0 License, which allows others to remix, tweak, and build upon the work non-commercially, as long as appropriate credit is given and the new creations are licensed under the identical terms.

For reprints contact: reprints@medknow.com

Cite this article as: Chamsi-Pasha $\mathrm{H}$, Chamsi-Pasha $\mathrm{M}$, Albar MA. Ethical dilemmas in the era of COVID-19. Avicenna J Med 2020;10:102-5. 
The criteria to allocate scarce lifesaving resources may make older adults, people from minority communities, or people with disabilities, vulnerable. Triage teams should be set up to implement criteria for prioritization, to minimize bias, and to avoid unintended negative consequences. Health systems should also prepare for the long-term psychological effects on the clinicians and families. ${ }^{[4]}$ Withdrawing ventilators from patients who arrived earlier, to save those with better prognosis, can be psychologically traumatic for the physicians, and some doctors may even refuse to do it. In patients with similar prognoses, providing the intensive care services should be equally invoked, and organized through random allocation, such as a "lottery," rather than adopting the first-come, first-served allocation process. ${ }^{[5]}$ There is "no ethically significant difference between decisions to withhold or withdraw treatments (if other factors are equal)." ${ }^{[6]}$ A national policy is urgently needed to provide the clinicians with clear guidance about how patients should be practically prioritized, when the available resources are limited. ${ }^{[7]}$

\section{PERSONAL PROTECTION EQUIPIMENT}

A major challenging ethical issue in this pandemic is the lack of adequate personal protection equipment (PPE) in most countries, with the consequent risk of catching the virus. This created a great pressure on the healthcare providers, in taking proper action, without violating the ethical principles. ${ }^{[8]}$ What would the clinician do if he is faced with a situation, where there is a lack of adequate PPE? Can he withhold treatment without any medicolegal consequences? And what are the legal sequels of such action? There is an obvious need for clear guidelines outlining the proper way of action, the clinician should take, in such scenarios. ${ }^{[9]}$

In the present pandemic, the physicians are the most valuable asset for the society, and sacrificing clinician's life without a proper PPE is probably considered an irresponsible act. ${ }^{[8]}$ Sadly, many physicians and other healthcare providers in Italy, United Kingdom, Egypt, and elsewhere, lost their lives during this pandemic.

\section{ETHICAL ISSUES OF THE VACCINE}

The world is extremely anxious to see the availability of an effective vaccine for the COVID-19. Once it is available, a number of ethical questions will emerge. Many researchers will continue to test the efficacy of other vaccines, for the same virus, in clinical trials involving human subjects. Is it ethical to conduct a trial on another vaccine and to deprive subjects in the trial from the benefit of an effective vaccine already in hand?
A robust principle in medical ethics is that no effective treatment or vaccine would be withheld from the patients, if their survival may rely on it. It is feared that such studies may be carried out in areas with less-resourced health systems, and hence there is a major concern that any trial withholding an efficient safe vaccine would probably affect the vulnerable populations who have been badly utilized with biomedical research in the past. ${ }^{[10]}$

On the contrary, one can argue that it is justifiable to conduct a trial with another vaccine, if it is expected to have clear advantage over the existing product. Thus, the burden is on the vaccine developers to convince the scientists that their potential vaccine is more appealing than the existing product, in terms of advantages and side effects. Both pharmaceutical companies and researchers conducting the vaccine trials should take all measures to protect the vulnerable research subjects. Such measures include providing appropriate compensation to the trial participants, and sharing the financial rewards of the successful vaccine with the involved communities. Besides, the informed consent should be obtained in culturally and linguistically appropriate way. ${ }^{[10]}$

\section{CLINICAL TRIALS}

In view of the urgency to obtain a vaccine or treatment of the COVID-19, many authorities fear that the design of randomized controlled trials (RCTs) may not be ideal, taking no account of the patients' essential interests. The investigators may loosen the inclusion and exclusion criteria, and fail to obtain a proper informed consent, particularly from the vulnerable subjects. Before the subject makes his/ her decision, the investigator should discuss with him/her the study aims and procedures, risks and benefits, and the rights and commitments of the participant. Even after the participant decides to share in the study, the research team should continue to provide the participant with any new information that might affect his situation, and provide him with reasonable compensation. Ethical committees should reemphasize these sensitive issues, and the researchers must maintain all efforts to not expose participants to any possible risks or harm. ${ }^{[11]}$ Investigators should realize that pandemics are not an excuse for relaxing the universal scientific standards, and researchers should always act according to the ethical principles. ${ }^{[12]}$

\section{PSYCHOLOGICAL EFFECTS}

The major burden of this pandemic is that healthcare providers are faced with huge number of patients to care for, and quite often, with limited resources. Worldwide, large number of patients with COVID-19 are seen dying 
in emergency rooms or intensive care units. At the same time, the majority of population throughout the world has been requested to reduce their activities, in the hope of minimizing the spread of the corona virus. All of these have created significant distress across the globe. ${ }^{[8]}$ In this era of rapid change, anxiety, social distancing, and financial burden, it is not unexpected to see that mental health, worldwide, might be at risk, and researchers have already initiated such research. ${ }^{[13]}$

\section{LABORING ALONE}

In order to protect both the healthcare providers and the patients during the pandemic, hospitals have taken the rules of prohibiting patient's visitors. In most hospitals, labor units have been considered as an exception to this rule. A "support person" during delivery is felt to have an "essential" role in the maternity care, and not having a partner around in labor or at the birth of a child is considered to be unkind, inconceivable, and for some, it may be traumatic.

Several hospitals in New York City were hit hard by the huge number of COVID-19 patients, and consequently, they imposed a ban on labor visitors, aiming at reducing staff exposures. The resulting reaction was a combination of ambiguity and resentment. Many obstetricians were worried that such policy may force women to arrange for home deliveries, or may force them to search for delivery at hospitals permitting the presence of supporting person. The "New York City Department of Public Health" published new guidance stating that a "support person" in labor is "essential," and the Governor of New York issued an order commanding hospitals to permit (healthy) visitors to be present during delivery. ${ }^{[14]}$

The notion of not having a "support person" during labor is unkind, and it may even be detrimental. However, one can argue that the same may apply to many patients left to die alone during this pandemic, without the presence or comfort of their loved ones. ${ }^{[14]}$ We are really facing an extraordinary situation in the history of medicine!

\section{VIOLENCE AGAINST WOMEN DURING PANDEMIC RESTRICTIONS}

Intimate partner violence (IPV) is considered as a major public health problem across the world, and it is more commonly referred to as "domestic violence." The World Health Organization (WHO) defines IPV as "any behavior within an intimate relationship that causes physical, psychological, or sexual harm to those in the relationship."
It is estimated that $30 \%$ of women, worldwide, experience some form of physical or sexual violence by their intimate partners in their lifetime. It is typically experienced by women but can also be experienced by men. ${ }^{[15]}$

Though robust data are scarce, media news and reports from the organizations, responding to domestic violence incidents, indicate that there is an alarming increase in the IPV cases during this pandemic. ${ }^{[16]}$

Although the healthcare system, worldwide, is under tremendous pressure as the pandemic overstretched the capacity of health institutions, the health sector should still take effective measures to alleviate the risk of violence against women during the pandemic. Healthcare providers should be aware of the risks and sequel of IPV, and provide the affected subjects with psychological and social support, in addition to the necessary medical treatment. The use of telemedicine and mobile health system, to safely support those affected with IPV, must be urgently explored. ${ }^{[16]}$

\section{CONCLUSION}

The COVID-19 pandemic raised unique ethical dilemmas, but the key issue has been the need to ration scarce critical care resources. There is a desperate need to substantially increase the resources dedicated to the health system, so that clinicians do not have to face the difficult decision of which life to save.

The intimate relationship between medicine and ethics is unequivocal, and the contribution of ethical perspective, particularly during the pandemic, is invaluable. Identifying the ethical challenges emerging from the pandemic will assist physicians in making proper decisions and in maintaining the best standards of care for their patients.

\section{Financial support and sponsorship}

Nil.

\section{Conflicts of interest}

There are no conflicts of interest.

\section{REFERENCES}

1. Fritz Z, Huxtable R, Ives J, Paton A, Slowther AM, Wilkinson D. Ethical road map through the COVID-19 pandemic. BMJ 2020;369: m2033.

2. Mannelli C. Whose life to save? Scarce resources allocation in the COVID-19 outbreak. J Med Ethics 2020;46:364-6.

3. Kramer JB, Brown DE, Kopar PK. Ethics in the time of coronavirus: Recommendations in the COVID-19 pandemic. J Am Coll Surg 2020;230:1114-8. 
4. Peterson A, Largent EA, Karlawish J. Ethics of reallocating ventilators in the COVID-19 pandemic. BMJ 2020;369:m1828.

5. Emanuel EJ, Persad G, Upshur R, Thome B, Parker M, Glickman A, et al. Fair allocation of scarce medical resources in the time of COVID-19. N Engl J Med 2020;382:2049-55.

6. Boyd K. Ethics in a time of coronavirus. J Med Ethics 2020;46: 285-6.

7. Cameron J, Savulescu J, Wilkinson D. Is withdrawing treatment really more problematic than withholding treatment? [published online ahead of print, 2020 May 25]. J Med Ethics 2020;medethics-2020-106330. doi:10.1136/medethics-2020-106330.

8. Angelos P. Surgeons, ethics, and COVID-19: Early lessons learned. J Am Coll Surg 2020;230:1119-20.

9. Arora A, Arora A. Ethics in the age of COVID-19 [published online ahead of print, 2020 May 21]. Intern Emerg Med 2020;1-2. doi: 10.1007/ s11739-020-02368-2.

10. Monrad JT. Ethical considerations for epidemic vaccine trials [published online ahead of print, 2020 May 15]. J Med Ethics. 2020;medethics-2020-106235. doi:10.1136/medethics-2020-106235.
11. Han Z, Wang J, Zhang K, Tang Q. The ethics of COVID-19 clinical trials: New considerations in a controversial area [published online ahead of print, 2020 May 15]. Integr Med Res 2020;9:100425.

12. Erren TC, Lewis P, Shaw DM. The COVID-19 pandemic: Ethical and scientific imperatives for "Natural" experiments [published online ahead of print, 2020 May 22]. Circulation. 2020; 10.1161/CIRCULATIONAHA.120.048671. doi:10.1161/CIRCULATIONAHA.120.048671

13. Townsend E, Nielsen E, Allister R, Cassidy SA. Key ethical questions for research during the COVID-19 pandemic. Lancet Psychiatry 2020;7:381-3.

14. Ecker JL, Minkoff HL. Laboring alone?: Brief thoughts on ethics and practical answers during the COVID-19 pandemic [published online ahead of print, 2020 May 15]. Am J Obstet Gynecol MFM 2020;100141.

15. WHO. WHO Global and regional estimates of violence against women: Prevalence and health effects of intimate partner violence and non-partner sexual violence. Geneva, Switzerland: World Health Organization; 2013. page 2. (checked on 6/12/2020).

16. Roesch E, Amin A, Gupta J, García-Moreno C. Violence against women during COVID-19 pandemic restrictions. BMJ 2020;369:m1712. 